\title{
Technical Route of Carbon Market Construction in China
}

\author{
Jing Xiao \\ School of Economics and Management, Changchun University of Science and Technology \\ Changchun 130021, China \\ E-mail: christieshaw@163.com \\ Jing Ma \\ School of Economics and Management, Changchun University of Science and Technology \\ Changchun 130021, China \\ Tel: 86-431-8580-3871Ｅ-mail: majingdoll@hotmail.com
}

\begin{abstract}
Nowadays, environmental protection has become the most public issue in the world. Thanks for the Kyoto Protocol that has established a trading system for greenhouse gas emissions worldwide; China has more chances to take part in environmental protection by carbon trading. But in recent years, carbon trading has been growing amazingly in China in volume but not in quality, which signs that it is meaningful to research on development of carbon market in China. The article describes the overview of carbon market, analyzes the prospect of carbon market, points out the necessity of carbon market construction in China and finally puts forward technical route of carbon market construction in China
\end{abstract}

Keywords: Emissions trading, Carbon market, Emission reduction

\section{Overview of Carbon Market}

Emissions trading, a market-based instrument used for environmental protection, has been adopted as one of the primary tools for international cooperation to reduce greenhouse gas (GHG hereafter) emissions under the Kyoto Protocol.

\subsection{Concept of Emissions Trading}

From the liquidity point of view, emissions trading can be effected by cash, equivalents, bonds, convertible stocks or even emission reduction technology.

From the real economy point of view, emissions trading refers to the companies or groups transacting their permitted carbon emissions right in different forms according to their cost of reducing emissions. Emission volume has an impact on emission reduction cost, then the companies or groups who emit less carbon than allowance have rights to sell the difference to the others who pollute more. The idea behind carbon emission trading is quite similar to the trading of securities or commodities in a marketplace. By taking climate factors into companies' balance sheet, carbon emission trading has made a change of industrial structure of income and expenses.

From the virtual economy point of view, in order to keep away the risks caused by uncertain climate changes and to obtain more sustainable profits, financial organizations have been developing a series of insurance products, derivatives and structural products related to carbon trading. Rights of carbon emission have become a kind of financial tool and their price is more and more determined by status of financial market. In other words, carbon emission rights are not a kind of simple product any more while financial capital having worked on it.

\subsection{Participants in Carbon Market}

The suppliers in carbon market are project developers, entities who enjoy the relatively low cost of reducing emissions, international financial organizations, carbon funds, banks, consultancies, companies who develop or transfer related technologies.

The demanders are compulsive buyers who have emissions limitation commitments under the Protocol; and voluntary buyers, including companies, governments, no-government organizations and even individuals who have no regulatory obligations to reduce their emissions. The latter purchase credits to offset part all of their emissions for the reasons of their social responsibilities or for the sake of their own sustainable development. 
Furthermore, Financial organizations have played important roles in the carbon market as middlemen. The financial participants involve brokers, exchanges, exchange platforms, banks, insurance companies, hedge funds and so on.

\subsection{Mechanism in Carbon Market}

Carbon market is a market for GHG emission reductions (credits) and rights to release GHG emissions (allowances). Although there are a number of different markets, the largest are established by the Kyoto Protocol and Parties that have emissions limitation commitments under three Protocol mechanisms, that is, Clean Development Mechanism (CDM), Joint Implementation and Emissions Trading (ET). The first mechanism mainly works on project-based market, and the next two on allowance-based market.

In allowance-based market, emissions are traded by the countries, organizations and corporations controlled by the assigned amounts listed in Annex B in the Protocol. The supervisors set down and allocate allowance to regulatory operators under the principles of total amount management and cap-and -trade system. This market operation enables the participants to fulfill their obligation of reducing emissions at the lowest cost.

In project-based market, emission reductions are formed under some projects. In practice, the corporations in the developed countries suffer a higher emissions reduction cost in their own countries than in the developing ones. As the result, they offer capital, technology, and equipments to assist corporate emission reduction in the developing or economic transformed countries, and in turn, enjoy the initial rights to buy the greenhouse gas emission margin. Some even resell the allowance in the international market.

At present, China mainly involves in project-based market.

\section{Prospects for Carbon Market}

\subsection{Active Regional Carbon Market}

Till now, there is no a globally unified carbon market, but the regional markets are active in the different parts of the world. The emissions trading systems established by Annex B Parties (EU ETS) have been the dominant regional carbon market in the world. It covers 27 numbers in the EU, The Principality of Liechtenstein and Norway, and includes about 12,000 entities emitting greenhouse gas. In the region, there are 8 trading platforms, including Bluenext (Paris, France), Climex (Amsterdam, the Netherlands), Energy Exchange Austria (Graz, Austria), European Climate Exchange (London, UK), European Energy Exchange (Leipzig, Germany), Nordic Power Exchange (Oslo, Norway), Italian Power Exchange market (Rome Italy) and International Association for Energy Economics (London, UK).

\subsection{Bigger Trade Volume and Higher Prices in Carbon Market}

According to the statistics from World Bank, trade volume increases at a surprising speed in carbon markets. The total volume of project-based transactions and allowances is US\$ 63 billion in 2007. And the overall carbon market continued to grow in 2008, reaching a total value transacted of about US\$ 126 billion at the end of the year, double its 2007 value. Approximately US\$ 92 billion of this overall value is accounted for by transactions of allowances and derivatives under EU ETS for compliance, risk management, arbitrage, raising cash and profit-making purposes. The second largest segment of the carbon market was the secondary market for Certified Emission Reductions (sCERs). As a financial market with spot, futures and options transactions in excess of US\$ 26 billion in 2008, it presents a five-fold increase in both value and volume over that in 2007.

The World Bank further estimates that carbon market will reach to US\$150 million and replace oil market as the biggest one in the world.

\subsection{Formation of Carbon Currency}

Carbon credit has become a kind of commodity and it will be used to exchange with carbon consumptions in the future. The expansion of carbon quotas and formation of more carbon trading platforms have become the firm foundation to promote pricing and settlement in the development of low carbon economy, low carbon energy and low carbon technologies by carbon credit. It is predicated that carbon credit, as a kind of complementary currency, will replace oil currency and change the currency system in the world. At present, euro is the most popular currency used in carbon pricing and settlement and US dollar or Yen are the second choice. At the same time Australian dollar and Canadian dollar have become more and more influential in carbon trading. We can see that most developed countries have realized the importance of carbon currency in the future and begin to take efforts to promote the position of their own currencies in the international carbon market. 


\section{Necessity of China's participating in Carbon Market Construction}

As a developing country, China is not included in the emission reduction plan during the period of 2008 to 2012 offered by the Kyoto Protocol. It is a good opportunity for China to shoot troubles on carbon emissions during it. But unfortunately, while becoming the largest seller, China has a dozen of troubles under way.

\subsection{China Becomes Dominate as a Seller}

The cost of emission reduction is 5 to 10 times higher in developed countries than that in developing ones, which has promoted the transfer of capital and carbon related technologies to China. In recent years, China has made great progress in Clean Development Mechanism (CDM) projects and the supply of certificated emission reductions (CER). More and more enterprises have involved in carbon trading. China, with a $73 \%$ market share in 2007 and $84 \%$ in 2008, accounts for the dominant share of confirmed transactions in the primary CDM market. Till October 2009, the CDM pipeline in China grew steadily to 2232 projects and 663 has been registered successfully in the executive council of Untied Union, creating the largest registered number and emission reduction volume in the world.

\subsection{Chinese Suffer losses from Floor Price}

Although Chinese corporations have created a large volume of GHG emission reductions, they are prohibited from selling their emission quotas to the western market directly. In reality, some developed countries and international funds purchase most CERs from China at the recommended floor price and transform them into more expensive financial products and derivatives after packing by their financial organizations. The developed countries also work hard to attract Chinese financial organizations to participate in their established carbon financial markets in order to obtain more profits from Chinese capital. For example, China sold CERs at a actual price of about 11 euro per tonne to the purchasers from the Europe in June last year. At the same period, the benchmark CER contract on the secondary market, for December 2014 delivery, traded at $€ 19$ on the European market.

At the same time, it is risky to sell emissions reduction at the floor price. We can see that emissions reduction is a kind of strategic resources. Once China begin to be controlled by emission cap, we should buy emissions reduction at a price even ten times higher than that we sell them now. the same thing has been happened for oil several decades before.

The main reason for what happen is that our carbon emissions are distributed in a wrong way. Then it is necessary to set up a unified national trading platform to conform resources as well as information, help form the reasonable prices in transactions and strengthen discourse power in pricing.

\subsection{Chinese Financial Organizations Drag Feet in Carbon Market Construction}

Nowadays, China has been on the way to construct her own carbon market and has got some progress such as the establishment of Beijing Environment Exchange, Shanghai Environment and Energy Exchange and Tianjin Climate Exchange. In this process, financial organizations should not only set up good environment in their daily operations but also be responsible for protecting environment by promoting their financial products and services. Whereas, China's financial organizations are not active enough in it. Here take China Sovereign Funds China Investment Corporation for example. It has a big size of foreign reserve exchanges, a convenient channel of coordinating with Chinese administrations that charge for climate change problems, and a capacity of communicating with international organizations like EU and financial companies in the world. However, it refuses to contribute to its effort to promote the construction of carbon market with an excuse of small scale of and imperfect regulations in this market.

\section{Technical Route of Carbon Market Construction in China}

The Kyoto Protocol expires in 2012. According to Bali roadmap and schedule formed in the Bali Conference, the $15^{\text {th }}$ session of UN Climate Change Conference has been hold in Copenhagen in December 2009. A series of global agreements have been formed during it. Chinese government put forward its target to reduce GHG emission per GNP $40 \%$ to $45 \%$ in 2020 compared with the level in 2005 . Although some western medias report that Chinese and Indian negotiators resist a treaty that includes binding emissions reduction targets, China as a developing country has done great efforts to fulfill her social obligations while protecting her fairly rights. Then it is clear that there are two main challenges encountered by China. On one hand, China has become the largest GHG emitter in the world and suffers more and more emission reduction pressures. On the other hand, we have not found an effective way to restrain GHG emissions by local emitters.

After analysis, China should do her best to set up carbon market as follows: 


\subsection{Set up Supervision Center}

A specialized center should be set up to guide and supervise the development of carbon market in China. The center will be in duty bound to design carbon trading mechanism suitable to China; harmonize the relationships among the government, corporations and financial organizations; perfect the rules and regulations related to the development of nationally unified, fair and efficient carbon market; and supervise exchange markets and related products.

According to the Kyoto Protocol, China has not been controlled by emission cap till 2012. In theory, national enterprises are not necessary to purchase emission rights to reimburse their own emissions. Whereas, we must prepare for what will happen after it. After establishment, the center's first task will be to regulate the emissions cap nationally, and divide it into parts to every province and then to every enterprise that should be involved or involves voluntarily. The difficulty is to decide the most suitable cap at every level and its operations in details.

\subsection{Set up a National Exchange Market further than Local markets}

It is be a significant step to set up a national environment and energy exchange market in China. Although the existing organizations such as carbon exchanges, CDM technological service center play well as exchange platforms and information platforms in local markets; they are chicken-shit in international market. The national exchange market helps us know more rules and information of international market, and it also tries for the real value of Chinese projects. It is a best tool to protect China's right position in the international market in the future.

Of course, the unified national carbon market cannot be formed without successfully local markets accumulation. The experimental platform for emissions trading should be set up for the transaction of more creative products related to GHG emission other than $\mathrm{CO} 2$ and $\mathrm{SO} 2$ directly and indirectly. Furthermore, more carbon markets should be set up locally, especially in some important area such as Yangtze River Delta and Pearl River Delta.

\subsection{Strengthen Financial Innovations}

China's local financial organizations should be more active to involving in the market by innovation of carbon-related financial products and services. Banks, non-bank financial organizations and institutional investors should carry out their social responsibilities and take opportunities in low-carbon world by innovating more environmental financial products, such as venture capital funds or investment funds on environmental related industries, loans to low carbon projects by commercial banks, and bonds on green finance.

We should set up environmental funds that which have been applied for in other countries. In general, it should be mainly invested by enterprises and supported by the government by all kinds of effective methods. After formation, it should focus on development of zero and low carbon technologies, evaluate emissions reduction potentials, encourage technological innovations and promote emissions reduction continuously. Furthermore, we should also set up multi-level national as well as local environmental funds to offer supports to low carbon projects, environmental protection projects, information services construction and etc. United Union, World Bank and other organizations have been successful in the research and utilization of environmental funds, which tells us how to do it effectively. We should combine their good experience with our own idea in our carbon financial innovations.

\subsection{Promote Related Services to Carbon Market}

Besides financial services, daily operations of the carbon market should be supported by other related services from some organizations, such as agencies operating between buyers and sellers, environmental consultancy companies and accreditation organizations certifying emissions rights. The agencies and consultancy companies will help dealers offer complete information, ensure transaction efficiency, and control costs. The accreditation organizations will work on validating emissions reduction by enterprises and offer certificate to enterprises that have reached to the target of emissions reduction. In a word, the construction of carbon market is the task not only of the nation or some enterprises but also of every social person

In conclusion, global carbon market will be formed in the near future. Before it, China should form her unified national one in order to work well internationally. When organizing both national support and individual efforts into carbon market construction in China, we should do more innovations beyond copy in aspect of operation target, management mechanism, and financial products. What we need is a carbon market suitable to China but perhaps not satisfying to other.

\section{References}

Adam Rose \& Dan Wei. (2008). Greenhouse Gas Emissions Trading among Pacific Rim Countries: An Analysis 
of Policies to Bring Developing Countries to the Bargaining Table. Energy Policy, 1420-1429.

D.Y.C. Leung, Daniel Yung \& Amanda Ng. (2009). An Overview of Emissions Trading and its Prospects in Hong Kong. Environment Science \&Policy, 92-101.

Julia Reinaud \& Cedric Philibert. (2008). Emissions Trading: Trends and Prospects. Paris France: OECD/IEA.

Lorate Stankeviciute, Alban Kitous \& Patrick Criqui. (2008). The Fundamentals of the Future International Emissions Trading System. Energy Policy, 4272-4286.

Niels Anger. (2008). Emissions Trading Beyond Europe: Linking Schemes. Energy Economics, 2028-2049.

UK. (2003). Energy White Paper: Our Energy Future - Creating a Low Carbon Economy. London: TSO, 1-8.

You Li, C. n. Hweitt. (2008). The Effect of Trade Between China and the UK on National and Global Carbon Dioxide Emissions. Energy Policy, 1907-1914. 